\title{
Morfologi Dan Sifat Optik Lapisan Tipis Opal yang Dideposisi Menggunakan Metode Modified Vertical Deposition
}

\author{
Sri Rahayu*, Muldarisnur \\ Laboratorium Fisika Material, Jurusan Fisika \\ Fakultas Matematika dan Ilmu Pengetahuan Alam Universitas Andalas \\ Kampus Unand Limau Manis, Padang, 25163 Indonesia \\ *Srirahayujamus@gmail.com
}

\begin{abstract}
ABSTRAK
Telah dilakukan pembuatan lapisan tipis opal dengan menggunakan metode modified vertical deposition. Pada penelitian ini dilakukan analisis pengaruh kecepatan penarikan substrat dari suspensi koloid polysterene terhadap sifat optik dan homogenitas ketebalan lapisan tipis opal. Pembuatan sampel dilakukan dengan kecepatan penarikan $1 \mathrm{~mm} / \mathrm{jam}, 5 \mathrm{~mm} / \mathrm{jam}, 10 \mathrm{~mm} / \mathrm{jam}$ dan $12 \mathrm{~mm} / \mathrm{jam}$. Sampel dikarakterisasi menggunakan mikroskop optik, spektrofotometer UV-Vis dan SEM (Scanning Electron Microscopy). Mikroskop Optik menunjukkan ketebalan lapisan opal yang tidak homogen. Karakterisasi UV-Vis menunjukkan adanya puncak absorbansi pada lapisan opal pada kecepatan $1 \mathrm{~mm} / \mathrm{jam}$ sedangkan SEM menunjukkan adanya lapisan opal yang multilayer (berlapis banyak) pada kecepatan penarikan 1 $\mathrm{mm} / \mathrm{jam}$.

Kata kunci: Lapisan tipis opal, Mikroskop Optik, SEM, UV-Vis, variasi kecepatan.
\end{abstract}

\section{ABSTRACT}

A thin layer of opal was deposited using modified vertical deposition method. This research is aimed at analyzing the effect of subtrate witdhrawal velocity from the colloidal suspension on optical properties and thickness homogenity of the thin opal film. Deposition of thin opal film were carried out by applying $1 \mathrm{~mm} / \mathrm{h}, 5 \mathrm{~mm} / \mathrm{h}, 10 \mathrm{~mm} / \mathrm{h}$, and $12 \mathrm{~mm} / \mathrm{h}$ of sample withdrawal speed. Opal sample were characteristic using optical microscope, UV-Vis spectrophotometer and SEM (scanning electron microscopy). Optical microscope images shows of that the thickness of the layer opal is not homogeneous. UV-Vis shows that the layer of opal has an absorbance in the opal layer. Absorption peak is observed only for sample with withdrawal speed of $1 \mathrm{~mm}$. sem shows images show that multilayer opal withdrawal speed of $1 \mathrm{~mm} / \mathrm{h}$. Keywords: Optical Microscope, SEM, UV-Vis, speed variation, thin opal layer.

\section{PENDAHULUAN}

Sistem telekomunikasi sekarang ini menggunakan serat optik dengan kapasitas pengiriman (band width) sangat tinggi. Dalam proses pengiriman informasi jarak jauh terjadi pelemahan sinyal akibat terjadinya dispersi cahaya dan interaksi antara modus terpandu. Akibatnya, sinyal pada serat optik harus diperkuat setiap $200 \mathrm{~km}$ menggunakan piranti elektronik. Penguatan sinyal ini, sinyal cahaya diubah menjadi sinyal listrik, diperkuat dan kemudian dikonversi lagi menjadi sinyal cahaya (Bagad, 2008).

Komponen elektronik ini relatif lambat, mudah panas dan band widthnya kecil sehingga perlu dikembangkan penguat optik terintegrasi. Pembuatan devais optik teringtegrasi pada substrat tunggal sulit dilakukan menggunakan bahan optik konvensional.

Pemantulan internal total menghalangi miniaturisasi devais optik karena pembengkokan (bending) akan mengakibatkan pelemahan sinyal terpandu karena sebagian sinyal diradiasikan. Miniaturisasi devais optik hanya dapat dilakukan dengan struktur buatan yang dinamakan kristal fotonik (Joannopoulous dkk., 2008).

Kristal fotonik adalah struktur periodik (dalam satu, dua, dan tiga dimensi) yang terbuat dari bahan dengan konstanta dielektrik berbeda dan periodisitas sebanding dengan panjang gelombang cahaya (Johnson dkk., 2012). Berdasarkan dimensi periodisitasnya, kristal fotonik dikelompokkan menjadi 1D, 2D dan 3D. Kristal fotonik 1D dan 2D memiliki kelebihan yaitu pembuatanya relatif mudah, namun terdapat daya yang hilang ke arah dimana strukturnya tidak periodik. Walaupun fabrikasinya relatif sulit, kristal fotonik 3D banyak diteliti karena memiliki band gap optik lengkap (full optical band gap) ke segala arah sehingga tidak ada cahaya yang hilang dalam perambatannya.

Secara umum ada dua pendekatan dalam fabrikasi kristal fotonik, yaitu top-down dengan menggunakan teknik litografi dan bottom-up dengan memanfaatkan kecenderungan 
partikel koloid melakukan self-assembly. Metode litografi merupakan metode standar dalam fabrikasi semikonduktor karena memiliki resolusi sangat tinggi, namun metode ini mahal dan lambat untuk membuat struktur 3D. Self assembly memanfaatkan kecenderungan alami nanopartikel koloid seperti silika, (poly methyl methacrylate) (PMMA) dan polystyrene untuk membentuk kristal koloid yang lebih dikenal dengan opal. Self assembly partikel koloid membentuk opal merupakan alternatif yang paling menjanjikan untuk menghasilkan kristal fotonik 3D karena mudah dan murah (Aiwei dkk., 2010). Partikel untuk deposisi opal harus berukuran seragam (monodispersi) agar bisa membentuk kristal. Partikel yang biasa digunakan adalah silika, PMMA, dan polysterene. Polysterene paling sering digunakan karena indeks biasnya lebih tinggi dibanding silika dan PMMA.

Berbagai metode sudah dikembangkan untuk menghasilkan opal dengan kualitas tinggi (Guojin dkk., 2014), seperti metode sedimentasi, deposisi horizontal, deposisi kapiler dan deposisi vertikal. Metode sedimentasi tidak dapat menghasilkan kristal tunggal dan hanya dapat digunakan untuk rentang ukuran partikel terbatas (Mi'guez dkk., 1998). Metode deposisi horizontal menghasilkan lapisan tipis opal dengan ketebalan yang tidak homogen. Metode deposisi vertikal dilakukan dengan mencelupkan substrat datar ke dalam kontrainer yang berisi suspensi partikel koloid. Penguapan pelarut pada meniskus akan menarik partikel kesana dimana terjadi kristalisasi partikel koloid (Ozin dkk., 2003). Metode ini lebih banyak digunakan dibandingkan metode yang lain karena menghasilkan sampel dengan konsentrasi cacat relatif rendah dengan waktu deposisi relatif singkat. Ketebalan lapisan tipis yang dihasilkan dengan metode ini bergantung pada konsentrasi partikel koloid di dalam suspensi. Metode deposisi vertikal biasanya menghasilkan ketebalan lapisan tipis yang tidak seragam. Ketidakhomogenan (gradien) ketebalan disebabkan oleh meningkatnya konsentrasi partikel koloid seiring penguapan pelarut.

Pada penelitian ini opal akan dideposisi dengan metode deposisi vertikal yang dimodifikasi dengan kecepatan penarikan sampel dari wadah suspensi. Penarikan dilakukan dengan menghubungkan substrat dengan motor servo yang dapat diatur kecepatannya. Penarikan sampel bertujuan untuk mengkompensasi penambahan kosentrasi akibat penguapan pelarut sehingga diharapkan didapatkan opal dengan kualitas tinggi dan dengan ketebalan yang homogen. Partikel koloid yang digunakan pada penelitian ini adalah polysterene berukuran 252 $\mathrm{nm}$. Sampel yang dihasilkan dikarakterisasi menggunakan spektrofotometri UV-Vis untuk mengukur absorbansi dan mengetahui posisi serta lebar celah pita optik. Morfologi lapisan tipis opal dikarakterisasi menggunakan Scanning Electron Microscopy (SEM) dan mikroskop optik.

\section{METODE}

\subsection{Alat Dan Bahan}

Alat yang digunakan untuk pembuatan lapisan tipis opal yaitu wadah suspensi dari teflon, hair dryer, neraca digital, ultrasonic bath, semprot air, pipet tetes, breaker glass, motor penggerak terdiri dari motor servo, arduino UNO, adaptor, UV-Vis Spektrofotometer, Scanning Elektron Mikroscopy, mikroskop optik. Bahan yang digunakan Partikel Polysterene $252 \mathrm{~nm}$, $\mathrm{SD}=0,006 \mathrm{Mm} 5 \% \mathrm{~W} / \mathrm{V}$ agueous suspension (Lot: $\mathrm{PS}=-\mathrm{R}-\mathrm{KM} 239$, dari microparticles Gmbh), aquabidest, aquades, substrat kaca $10 \mathrm{~mm}$ X $25 \mathrm{~mm}$, pembersih kaca mata.

\subsection{Preparasi substrat kaca}

Proses preparasi substrat kaca dimulai dengan kaca dipotong $10 \mathrm{~mm}$ x $25 \mathrm{~mm}$. Lalu dibersihkan kaca dengan pemebersih kaca mata. Setelah itu dikeringkan dengan hair dryer .

\subsection{Pembuatan lapisan tipis opal}

Proses pembuatan lapisan tipis opal melalui beberapa tahap, substrat dicelupkan ke dalam wadah suspensi yang berisi suspensi partikel koloid. Penguapan pelarut pada meniskus akan menarik partikel, dimana terjadi kristalisasi koloid. Sampel yang telah terbentuk ditarik dengan kecepatan $1 \mathrm{~mm} / \mathrm{jam}, 5 \mathrm{~mm} / \mathrm{jam}, 10 \mathrm{~mm} / \mathrm{jam}, 12 \mathrm{~mm} / \mathrm{jam}$. Setelah ditarik sampel dikeringkan pada suhu ruang untuk menghilangkan sisa pelarut. 


\subsection{Karakterisasi lapisan tipis opal}

Sampel dikarakterisasi dengan menggunakan UV-VIS Spektrofotometer untuk melihat celah pita optik pada penumbuhan lapisan tipis opal, Scanning Electron Microscopy (SEM) digunakan untuk memperoleh informasi mengenai topografi dan morfologi lapisan tipis opal dan mikroskop optik digunakan untuk melihat homogenitas lapisan tipis yang tebentuk.

\section{HASIL DAN DISKUSI}

\subsection{Hasil sintesis lapisan tipis opal}

Lapisan tipis opal yang disintesis diperlihatkan pada Gambar 1. Lapisan tipis opal hanya terlihat pada sampel A yang dideposisi dengan kecepatan penarikan terkecil yaitu 1 $\mathrm{mm} / \mathrm{jam}$. Sampel B-C-D tidak menunjukkan adanya lapisan opal sama sekali. Ketebalan lapisan opal sampel A tidak homogen. Kebergantungan dipengaruhi oleh laju kristalisasi dan kecepatan penarikan partikel yang tidak seimbang.
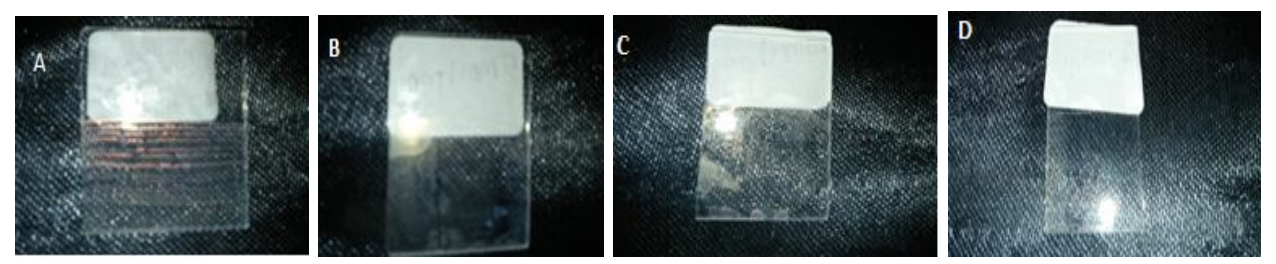

Gambar 1 (A) hasil sintesis lapisan tipis opal dengan variasi kecepatan,

$1 \mathrm{~mm} / \mathrm{jam}$, (B) kecepatan $5 \mathrm{~mm} / \mathrm{jam}$, (C) kecepatan $10 \mathrm{~mm} / \mathrm{jam}$, (D) kecepatan $12 \mathrm{~mm} / \mathrm{jam}$.

\subsection{Hasil analisis Mikroskop Optik}

Pengukuran dengan mikroskop optik dilakukan untuk melihat homogenitas lapisan tipis yang terbentuk. Homogenitas permukaan sampel dilihat dengan perbesaran 40x.
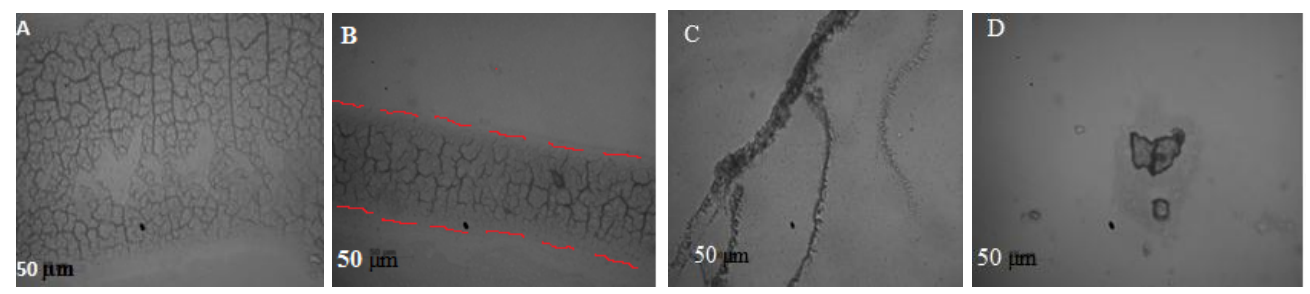

Gambar 2 (A) hasil foto Mikroskop Optik kecepatan $1 \mathrm{~mm} / \mathrm{jam}$, (B) kecepatan $5 \mathrm{~mm} / \mathrm{jam}$, (C) kecepatan $10 \mathrm{~mm} / \mathrm{jam}$ (D) kecepatan $12 \mathrm{~mm} / \mathrm{jam}$.

Gambar 2 menampilkan informasi tentang homogenitas permukaan sampel lapisan tipis opal yang terbentuk. Gambar A memperlihatkan permukaan lapisan opal dengan ketebalan cukup homogen. Gambar B hasil yang didapatkan lebih tebal dibandingkan dengan sampel C dan D walaupun permukaan yang didapatkan masih belum homogen. Lapisan tipis opal pada Gambar B memiliki ketebalan yang tidak homogen. Sampel C dan D tidak terbentuk opal sama sekali karena kecepatan yang digunakan teralu besar. Kebergantungan dipengaruhi oleh laju kristalisasi dan kecepatan penarikan partikel yang tidak seimbang.

\subsection{Morfologi Lapisan Tipis Opal}

Karakterisasi SEM dilakukan untuk mengetahui morfologi permukaan pada sampel lapisan tipis. Gambar 3 menunjukkan bahwa ketebalan lapisan tipis opal yang terbentuk belum homogen. Skala batang (scale bar) pada Gambar SEM dalah $1 \mu \mathrm{m}$ dengan perbesaran 10.000 kali dan ukuran partikel polysterene $250 \mathrm{~nm}$. Foto SEM untuk sampel A, B, C dan D dapat dilihat pada Gambar 3. 

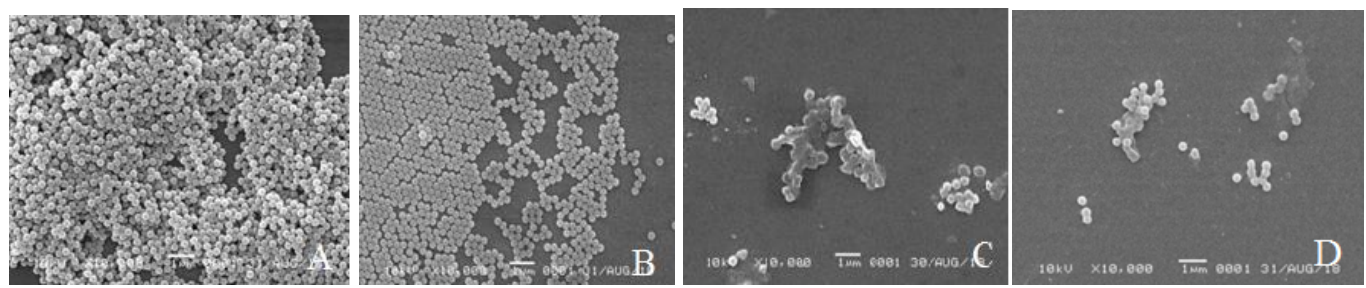

Gambar 3 (A) Gambar SEM dengan perbesaran 10.000 kali Morfologi permukaan lapisan tipis opal dengan variasi kecepatan $1 \mathrm{~mm} / \mathrm{jam}$, (B) kecepatan $5 \mathrm{~mm} / \mathrm{jam}$, (C) kecepatan 10 $\mathrm{mm} / \mathrm{jam}$, dan (D) kecepatan $12 \mathrm{~mm} / \mathrm{jam}$.

Berdasarkan Gambar 3 (A) dapat dilihat bahwa lapisan yang didapatkan multilayer (berlapis banyak). Gambar (B) didapatkan lapisan yang monolayer (satu lapis). Gambar (C) dan (D) tidak terdapat lapisan karena tidak terjadi kristalisasi. Kebergantungan dipengaruhi oleh laju kristalisasi dan kecepatan penarikan partikel yang tidak seimbang.

\subsection{Sifat Optik Opal}

Spektrofotometer UV-Vis memberikan informasi tentang posisi bandgap, lebar bandgap, intensitas, dan absorbansi maksimum dari lapisan tipis opal. Spektrum UV-Vis lapisan opal dapat dilihat pada Gambar 4.

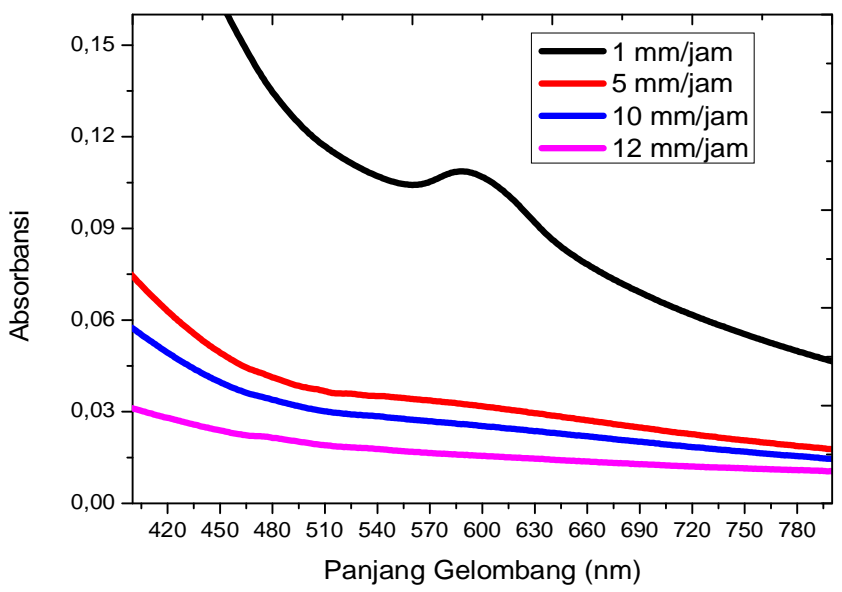

Gambar 4 Spektrum absorbansi UV-Vis lapisan tipis opal yang dideposisi dengan metode modified vertical deposition dengan kecepatan penarikan $1 \mathrm{~mm} / \mathrm{jam}, 5 \mathrm{~mm} / \mathrm{jam}, 10 \mathrm{~mm} / \mathrm{jam}$ dan $12 \mathrm{~mm} / \mathrm{jam}$.

Gambar 4 memperlihatkan spektrum UV-Vis dari keempat sampel yang telah disintesis. Spektrum yang ditampilkan sudah dikurangi dengan absorbansi substrat kaca. Sampel B, C dan D tidak memperlihatkan puncak absorbansi. Sampel A dengan kecepatan penarikan 1 $\mathrm{mm} /$ jam memiliki puncak absorbansi pada panjang gelombang $588 \mathrm{~nm}$ dengan nilai absorbansi maksimum 0,1542. Puncak absorbansi mengidentifikasikan terbentuknya celah optik pada lapisan tipis opal. Kebergantungan dipengaruhi olehlaju kristalisasi dan kecepatan penarikan. Kecepatan yang terlalu besar mengakibatkan tidak terbentuknya opal. Tidak terbentuknya opal mengakibatkan tidak terbentuk bandgap, sehingga tidak terdapat puncak absorbansi. Nilai absorbansi maksimum didapatkan anatara perbandingan hubungan nilai absorbansi maksimum terhadap kecepatan penarikan sampel. Hal ini terjadi karena semakin lambat kecepatan penarikan maka nilai absorbansi maksimum akan semakin besar. 


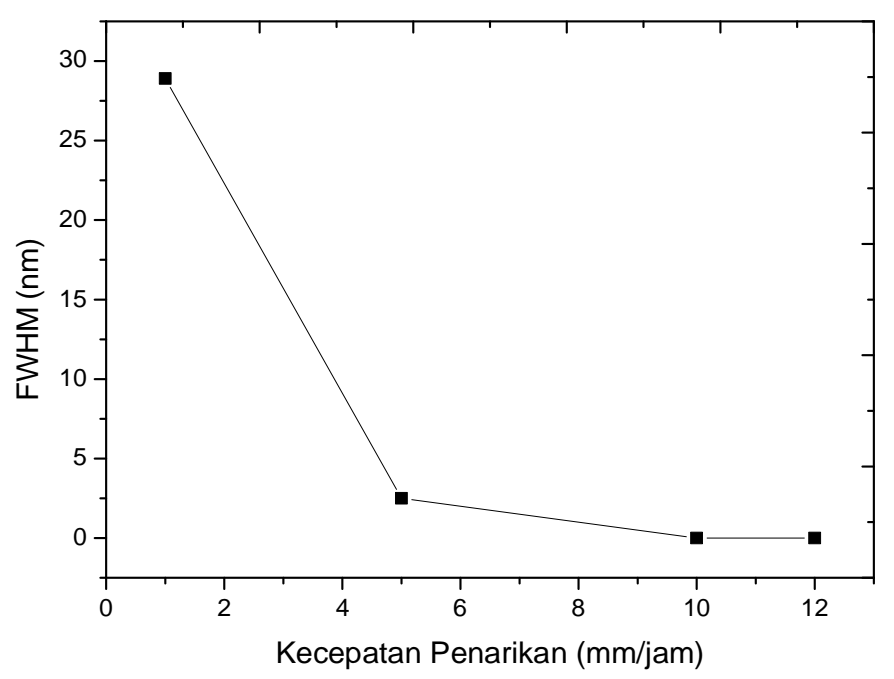

Gambar 5 Kebergantungan lebar bandgap terhadap kecepatan penarikan.

Gambar 5 Menunjukkan hubungan nilai FWHM dengan kecepatan penarikan. Kecepatan penarikan menunjukkan perubahan signifikan yaitu semakin besar kecepatan penarikan maka opal tidak periodik. Semakin besar kecepatan penarikan maka tidak terbentuk bandgap. Nilai FWHM didapatkan dari $\lambda 1-\lambda 2$ yaitu sebesar $28,90 \mathrm{~nm}$ dan energi gap sebesar $0,1 \mathrm{eV}$.

\section{KESIMPULAN}

Berdasarkan hasil penelitian yang telah dilakukan diperoleh kesimpulan bahwa kecepatan penarikan mempengaruhi homogenitas dan sifat optik lapisan tipis opal yang dihasilkan. Lapisan opal hanya terbentuk pada kecepatan penarikan $1 \mathrm{~mm} / \mathrm{jam}$. Kecepatan penarikan sampel yang lebih tinggi tidak menghasilkan opal. Pada kecepatan penarikan 5 $\mathrm{mm} / \mathrm{jam}$ hanya terbentuk lapisan yang monolayer (satu lapis). Semakin lambat kecepatan penarikan, semakin lebar FWHM dari puncak absorbansi.

\section{DAFTAR PUSTAKA}

Aiwei, T., Shengchun,Q., Kai, L., Yanbing,H., Feng,T., Jie,C., Youngsheng,W., and Zhongue,W., 2010, One Pot Synthesis and Self Assembly of Colloidal Copper (1) Sulfide Nanocrystals ,nanotechnology, Vol.21, hal.285602.

Bagad, S., 2008, Optical Fiber Communication, Technical Publications, Pune.

Guojin,L., Lan,Z., Yujiang,W., Cuicui,W., Qinguo,F,, Jianzhong,S., 2014, The Fabrication of Full Color P(St-MAA) Photonic Crystal Structure on Polyester Fabrics by Vertical Deposition Self-assembly, Journal of Applied Polymer Science, Vol. 41750, hal.1-9.

Joannopoulos, J.D., Johnson, S.G., Winn, J.N., and Meade, R. D., 2008, Photonic Crystals Molding the Flow of Light, Princeton University Press, New Jersey.

Míguez, H., Meseguer, F., López, C., Blanco, I., Moya ,J.S., Requena, J., Mifsud, A., FornØs, V., 1998, Control of the Photonic Crystal Properties of fcc-Packed Submicrometer $\mathrm{SiO}_{2}$ Spheres by Sintering. Advanced Materials, Vol.10, hal.480-483.

Ozin,G. A., Wong, S., Kitaev, V., 2003, Colloidal crystal films: Advances in universality and perfection, Journal of the American Chemical Society, Vol.125, hal. 15589. 